\title{
Predictors of 30-Day Mortality in the Era of Reperfusion for Acute Myocardial Infarction
} Results From an International Trial of 41021 Patients

\author{
Kerry L. Lee, PhD; Lynn H. Woodlief, MS; Eric J. Topol, MD; W. Douglas Weaver, MD; \\ Amadeo Betriu, MD; Jacques Col, MD; Maarten Simoons, MD; Phil Aylward, MD; \\ Frans Van de Werf, MD; Robert M. Califf, MD, for the GUSTO-I Investigators
}

\begin{abstract}
Background Despite remarkable advances in the treatment of acute myocardial infarction, substantial early patient mortality remains. Appropriate choices among alternative therapies and the use of clinical resources depend on an estimate of the patient's risk. Individual patients reflect a combination of clinical features that influence prognosis, and these factors must be appropriately weighted to produce an accurate assessment of risk. Prior studies to define prognosis either were performed before widespread use of thrombolysis or were limited in sample size or spectrum of data. Using the large population of the GUSTO-I trial, we performed a comprehensive analysis of relations between baseline clinical data and 30-day mortality and developed a multivariable statistical model for risk assessment in candidates for thrombolytic therapy.

Methods and Results For the 41021 patients enrolled in GUSTO-I, a randomized trial of four thrombolytic strategies, relations between clinical descriptors routinely collected at initial presentation, and death within 30 days (which occurred in $7 \%$ of the population) were examined with both univariable and multivariable analyses. Variables studied included demographics, history and risk factors, presenting characteristics, and treatment assignment. Risk modeling was performed with logistic multiple regression and validated with bootstrapping techniques. Multivariable analysis identified age as the most significant factor influencing 30-day mortality, with rates of $1.1 \%$ in the youngest decile ( $<45$ years) and $20.5 \%$ in patients
\end{abstract}

$>75$ (adjusted $\chi^{2}=717, P<.0001$ ). Other factors most significantly associated with increased mortality were lower systolic blood pressure $\left(\chi^{2}=550, P<.0001\right)$, higher Killip class $\left(\chi^{2}=350, P<.0001\right)$, elevated heart rate $\left(\chi^{2}=275, P<.0001\right)$, and anterior infarction $\left(\chi^{2}=143, P<.0001\right)$. Together, these five characteristics contained $90 \%$ of the prognostic information in the baseline clinical data. Other significant though less important factors included previous myocardial infarction, height, time to treatment, diabetes, weight, smoking status, type of thrombolytic, previous bypass surgery, hypertension, and prior cerebrovascular disease. Combining prognostic variables through logistic regression, we produced a validated model that stratified patient risk and accurately estimated the likelihood of death.

Conclusions The clinical determinants of mortality in patients treated with thrombolytic therapy within 6 hours of symptom onset are multifactorial and the relations complex. Although a few variables contain most of the prognostic information, many others contribute additional independent prognostic information. Through consideration of multiple characteristics, including age, medical history, physiological significance of the infarction, and medical treatment, the prognosis of an individual patient can be accurately estimated. (Circulation. 1995;91:1659-1668.)

Key Words - myocardial infarction - prognosis • risk factors • thrombolysis

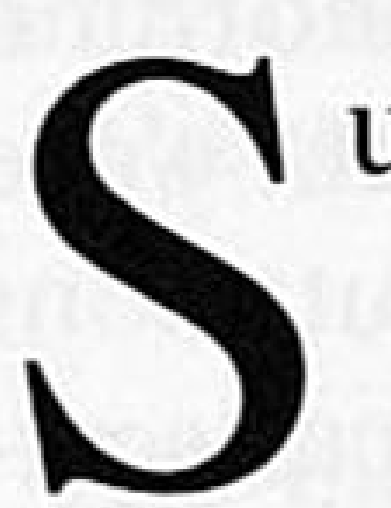
ubstantial advances in the treatment of acute myocardial infarction (MI) have occurred over the past several years as a result of important observations in basic myocardial research and through the vital evaluative mechanism of randomized clinical

Received May 12, 1994; revision received September 29, 1994; revision accepted October 14, 1994.

From the Departments of Community and Family Medicine (Biometry) (K.L.L.) and Medicine (Cardiology) (L.H.W., R.M.C.), Duke University Medical Center, Durham, NC; the Department of Cardiology, Cleveland (Ohio) Clinic Foundation (E.J.T.); the Department of Medicine (Cardiology), University of Washington, Seattle (W.D.W.); Hospital Clinic I, Barcelona, Spain (A.B.); Clinique Universitaire St Luc, Bruxelles, Belgium (J.C.); the Thoraxcenter, Erasmus Universiteit, Rotterdam, The Netherlands (M.S.); the Department of Cardiovascular Medicine, Flinders Medical Center, Bedford Park, SA, Australia (P.A.); and the Department of Cardiology, University of Leuven (Belgium) (F. Van de W.).

Correspondence to Kerry L. Lee, PhD, Associate Professor, Biometry Division, Community and Family Medicine, Box 3363, Duke University Medical Center, Durham, NC 27710.

(C) 1995 American Heart Association, Inc. trials. ${ }^{1-10}$ Practitioners now have a variety of treatment strategies available, especially for patients with STsegment elevation, to restore obstructed coronary blood flow and interrupt the evolving myocardial event. Despite therapeutic advances, recent large-scale randomized clinical trials report $6 \%$ to $9 \%$ early mortality rates (30 to 35 days), even for patients receiving thrombolytic therapy within 6 hours of symptom onset. ${ }^{11-14}$ Often, choices among alternative therapies or decisions regarding the allocation of clinical resources are based on an assessment of patient risk. Careful attention to pivotal factors that increase the risk of early mortality might illuminate the role of second-tier interventions or adjunctive pharmacotherapeutics that would further lower the fatality rate of acute MI.

To be broadly useful, a risk-assessment algorithm should include all clinically relevant prognostic indicators and should be derived from a population that represents the types of patients seen in clinical practice so that stable estimates of true risk relations can be assessed. A useful model should appropriately weight 
clinically relevant predictors and be validated in a population with a broad spectrum of patients and hospital settings, in which risk profiles may soon be required. Though many studies have attempted to define the prognosis of patients with MI and/or provide risk algorithms, ${ }^{15-23}$ they were performed before the widespread use of thrombolytic agents ${ }^{15-19}$ or were limited in sample size, diversity of medical care systems, or spectrum of clinical data.

Using the large population of the international Global Utilization of Streptokinase and Tissue Plasminogen Activator for Occluded Coronary Arteries (GUSTO-I) trial (41 021 patients admitted to 1081 hospitals in 15 countries) ${ }^{14}$ we attempted to provide a comprehensive analysis of relations between baseline clinical factors and 30-day mortality after intravenous thrombolytic therapy. The goal was to develop a multivariable statistical model with patient data routinely collected at initial presentation that would be clinically useful in managing patients who are candidates for thrombolytic therapy.

\section{Methods}

\section{Patient Population}

The GUSTO-I trial enrolled 41021 patients with acute MI presenting with ST-segment elevation (within 6 hours of symptom onset) between December 27, 1990, and February 22, 1993. The design and data collection methods of GUSTO-I were described previously. ${ }^{14}$ Patients were randomized over the telephone, with selected baseline characteristics recorded to ensure eligibility. Exclusion criteria included a history of stroke, active or recent bleeding history or major coagulation abnormality, recent trauma or major surgery, noncompressible vascular punctures, and previous treatment with streptokinase or anistreplase (because of possible allergic reactions). There were no restrictions based on age, presentation in cardiogenic shock, or prior bypass surgery.

\section{Treatments}

Qualifying patients were randomly allocated to one of four treatment strategies: streptokinase 1.5 million $\mathrm{U}$ over $60 \mathrm{~min}$ utes with subcutaneous heparin $12500 \mathrm{U}$ twice daily, beginning 4 hours after the start of thrombolytic therapy; streptokinase 1.5 million $\mathrm{U}$ over 60 minutes with intravenous heparin bolus of $5000 \mathrm{U}$ and then $1000 \mathrm{U} / \mathrm{h}$, with dose adjustment to maintain an activated partial thromboplastin time of 60 to 85 seconds; accelerated tissue-plasminogen activator (TPA) bolus of $15 \mathrm{mg}$ and then infusion of $0.75 \mathrm{mg} / \mathrm{kg}$ (up to $50 \mathrm{mg}$ ) over 30 minutes and $0.5 \mathrm{mg} / \mathrm{kg}$ (up to $35 \mathrm{mg}$ ) over the next 60 minutes, accompanied by the same intravenous heparin regimen; or a combination of intravenous TPA $(1.0 \mathrm{mg} / \mathrm{kg}$ over 60 minutes, not to exceed $90 \mathrm{mg}$, with $10 \%$ given as a bolus) and streptokinase (1.0 million $\mathrm{U}$ over 60 minutes) given concurrently but through separate catheters, accompanied by the same intravenous heparin regimen. ${ }^{14}$

\section{Baseline Clinical Information}

Baseline clinical data were collected on all patients with a standard data collection form. Specific written instructions and definitions for each variable were provided to all sites for use in completing the forms. Definitions of the clinical variables in this trial were used in previous studies. ${ }^{14,24}$ Extensive quality control checks have been used at the time of data entry, and missing or questionable answers were queried. A sample of $12 \%$ of the forms was audited by a comparison of the data on the form with hospital medical records.

\section{End-Point Assessment}

The primary end point of the trial was death from any cause within 30 days of randomization. The study coordinator at each site recorded mortality information for patients who died in the hospital. Mortality data after discharge but within 30 days were obtained by a postcard returned by patients or their families. When no postcard was received, follow-up status was determined over the telephone.

\section{Statistical Methods}

Baseline characteristics of study patients were summarized in terms of frequencies and percentages for categorical variables and by the median and 25 th and 75 th percentiles for continuous variables. A logistic multiple regression model25,26 was used to examine individual and joint relations between baseline clinical characteristics and the binary outcome of death within 30 days of randomization. For continuous clinical variables, we examined the shape and strength of the relation between individual variables and 30-day mortality by use of a flexible model-fitting approach involving cubic spline functions (cubic polynomials). ${ }^{27-31}$ These functions were graphically and statistically examined to assess the assumption of this regression model that patient characteristics are linearly related to the log odds of the outcome event (30-day mortality). Where relations were nonlinear, their shape was characterized with spline functions. Determining how variables should be modeled was an important step in characterizing prognostic relations and identifying which variables were most strongly related to short-term mortality. We also examined whether the prognostic relation of any important variable differed for particular levels of other important descriptors (ie, we tested for interactions among the prognostic clinical variables).

Among the array of clinical characteristics considered potential predictor variables in the modeling analyses were occasional patients with missing values. Although a full set of analyses was performed in patients with complete data for all the important predictor variables ( $92 \%$ of the study patients), the subset of patients with one or more missing predictor variables had a higher mortality rate than the other patients, and excluding those patients could lead to biased estimates of risk. To circumvent this, a method for simultaneous imputation and transformation of predictor variables based on the concepts of maximum generalized variance and canonical variables was used to estimate missing predictor variables and allow analysis of all patients. ${ }^{33,34}$ The iterative imputation technique conceptually involved estimating a given predictor variable on the basis of multiple regression on (possibly) transformed values of all the other predictor variables. End-point data were not explicitly used in the imputation process. The computations for these analyses were performed with s-PLuS statistical software (version 3.2 for UNIX ${ }^{32}$ ), using a modification of an existing algorithm. ${ }^{33,34}$ The imputation software is available electronically in the public domain. ${ }^{33}$

The full study population was used in the model development process, and the predictive performance of the model was internally validated through cross validation and bootstrapping. ${ }^{35-39}$ First, 10 -fold cross validation was performed: the model was fitted on a randomly selected subset of $90 \%$ of the study patients, and the resulting fit was tested on the remaining $10 \%$. This process was repeated 10 times to estimate the extent to which the predictive accuracy of the model (based on the entire sample) was overoptimistic. Second, for each of 100 bootstrap samples (samples of the same size as the original population but with patients drawn randomly, with replacement, from the full study population), the model was refitted and then tested on the original sample, again to estimate the degree to which the predictive accuracy of the model would be expected to deteriorate when applied to an independent sample of patients. ${ }^{39}$ The software used for model validation is also available electronically in the public domain. ${ }^{40}$ 
TABle 1. Baseline Characteristics of Patients in the GUSTO-I Mortality Analysis

\begin{tabular}{|c|c|c|}
\hline & $\begin{array}{l}\text { Overall Population } \\
\qquad(n=40830)\end{array}$ & $\begin{array}{c}\text { Deaths } \\
(n=28151)\end{array}$ \\
\hline \multicolumn{3}{|l|}{ Demographics } \\
\hline Age, y & $62(52,70)$ & $72(64,78)$ \\
\hline Male & 75 & 59 \\
\hline White & 92 & 92 \\
\hline Weight, kg & $78(70,88)$ & $73(64,82)$ \\
\hline Height, cm & $172(165,178)$ & $168(160,175)$ \\
\hline Enrolled in United States & 56 & 55 \\
\hline \multicolumn{3}{|l|}{ Risk factors } \\
\hline Hypertension & 38 & 47 \\
\hline Diabetes & 15 & 23 \\
\hline \multicolumn{3}{|l|}{ Smoking status } \\
\hline Current & 43 & 26 \\
\hline Ex-smoker & 27 & 28 \\
\hline Never smoked & 30 & 46 \\
\hline Hypercholesterolemia & 34 & 27 \\
\hline Family history & 42 & 32 \\
\hline \multicolumn{3}{|l|}{ Other history } \\
\hline Previous MI & 16 & 28 \\
\hline Previous angina & 37 & 45 \\
\hline Cerebrovascular disease & 2 & 5 \\
\hline Prior bypass surgery & 4 & 7 \\
\hline Prior angioplasty & 4 & 3 \\
\hline \multicolumn{3}{|l|}{ Presenting characteristics } \\
\hline Systolic BP, mm Hg & $130(112,144)$ & $120(100,140)$ \\
\hline Diastolic BP, mm Hg & $80(70,90)$ & $74(61,85)$ \\
\hline Heart rate, bpm & $74(62,86)$ & $80(67,96)$ \\
\hline \multicolumn{3}{|l|}{ Infarct location } \\
\hline Anterior & 39 & 56 \\
\hline Inferior & 58 & 41 \\
\hline Other & 3 & 4 \\
\hline \multicolumn{3}{|l|}{ Killip class } \\
\hline 1 & 85 & 63 \\
\hline II & 13 & 25 \\
\hline III & 1 & 6 \\
\hline IV & 1 & 6 \\
\hline \multicolumn{3}{|l|}{ Time course } \\
\hline $\begin{array}{l}\text { Symptom onset to } \\
\text { randomization, min }\end{array}$ & $120(80,180)$ & $135(90,210)$ \\
\hline $\begin{array}{l}\text { Symptom onset to } \\
\text { treatment, min }\end{array}$ & $165(120,235)$ & $185(130,260)$ \\
\hline
\end{tabular}

$\mathrm{MI}$ indicates myocardial infarction; BP, blood pressure. Values are the median (25th, 75 th percentiles) for continuous variables or the percentage of patients in each category.

The measure of predictive discrimination used to characterize model performance, in both the original sample and the validation samples, was the area under the receiver operating characteristic curve. ${ }^{41}$ This index measures the concordance of predictions with actual outcomes (how well the predictions rank order patients with respect to their outcomes) and is a simple transformation of Somer's $D_{x y}$ rank correlation between the model predictions and actual outcomes. ${ }^{42}$ Calibration of the model predictions was assessed by comparison of the average model prediction to the observed mortality rate across deciles of risk and among specific subgroups of patients with different risk levels. ${ }^{43}$

\section{Results}

Thirty-day mortality status was known in 40830 patients $(99.5 \%)$. Table 1 summarizes the baseline clinical characteristics of this population. The demographics and clinical characteristics of these patients encompass the spectrum of acute MI patients who present with STsegment elevation and are considered eligible for throm- bolytic therapy based on GUSTO-I entry criteria. As previously reported, ${ }^{14}$ there were no differences in baseline characteristics among the four treatment groups in the trial. A total of 2851 patients $(7.0 \%)$ died within 30 days of study enrollment. Thirty-nine percent of the deaths (1125) occurred within 24 hours; more than half $(55 \%)$ occurred within 48 hours of randomization.

In Table 2, 30-day mortality rates are reported for each categorical baseline characteristic, accompanied by univariable $\chi^{2}$ statistics and unadjusted odd ratios (ORs), reflecting the degree of risk stratification associated with each characteristic when considered alone. The most significant factor among these variables was Killip class at enrollment. Although relatively few patients presented in Killip class III or IV $(2 \%)$, their mortality rate was very high. The other more significant univariable predictors of higher mortality were female sex, anterior wall MI, history of previous MI, and history of diabetes. Smoking status was a highly significant univariable predictor, with current or prior smoking associated with lower mortality.

Fig 1 shows the univariable prognostic relations for continuous baseline characteristics. The most significant prognostic factor among this group of variables was age, where beyond 60 years there was a dramatic effect of increasing age on mortality. A strong prognostic relation was also present for systolic blood pressure, notably in the range below $120 \mathrm{~mm} \mathrm{Hg}$. A similar but less significant pattern existed for diastolic blood pressure. Heart rate at entry displayed a significant $U$-shaped relation, with elevated mortality at very low and at high heart rates. Weaker prognostic relations were demonstrated for both weight and height, with lighter and shorter patients exhibiting slightly higher risk. In patients who were treated more than 2 hours from symptom onset, the risk of mortality gradually increased with longer time to treatment. Compared with the other clinical factors in Fig 1, the relation between time to treatment and mortality was less significant.

In the multivariable analysis, many characteristics significantly associated with mortality in univariable analysis remained important (Table 3 ). Variables that were not significant, however, included prior angina, prior angioplasty, diastolic blood pressure, and family history of coronary heart disease. Female sex $(P=.043)$ and enrollment in the United States $(P=.047)$ had borderline relations with outcome after adjustment for the other prognostic variables and thus were not included in the final multivariable model. The variable demonstrating the strongest independent relation with 30-day mortality was age. Even after adjustment for the other important clinical factors, patients at the upper quartile of the age distribution in this population (70 years) were nearly four times more likely to die within 30 days than patients at the lowest quartile (52 years; adjusted OR, 3.88; 95\% CI, 3.52 to 4.28). The other more significant independent predictors of mortality were systolic blood pressure, Killip class, heart rate, and MI location.

Only one interaction among these factors was significant to the degree that it was appropriate to include in the model-the interaction between age and Killip class. The prognostic effect of age was reduced somewhat among patients with a more severe Killip class at entry, 
TABLE 2. Unadjusted Mortality Rates and ORs for Categorical Baseline Characteristics

\begin{tabular}{|c|c|c|c|c|c|}
\hline Variable & Category & Mortality Rate, \% & $x^{2}$ & OR & $95 \% \mathrm{Cl}$ \\
\hline \multirow[t]{2}{*}{ Sex } & Female & 11.3 & 391 & 2.17 & $(2.01,2.35)$ \\
\hline & Male & 5.5 & & & \\
\hline \multirow[t]{2}{*}{ Race } & Caucasian & 7.0 & 0.15 & 0.97 & $(0.85,1.12)$ \\
\hline & Other & 7.1 & & & \\
\hline \multirow[t]{2}{*}{ Country } & United States & 6.8 & 2.9 & 0.94 & $(0.87,1.01)$ \\
\hline & Non-United States & 7.2 & & & \\
\hline \multirow[t]{2}{*}{ Hypertension } & Yes & 8.5 & 103 & 1.49 & $(1.38,1.61)$ \\
\hline & No & 5.9 & & & \\
\hline \multirow[t]{2}{*}{ Diabetes } & Yes & 10.6 & 155 & 1.79 & $(1.64,1.97)$ \\
\hline & No & 6.2 & & & \\
\hline \multirow[t]{3}{*}{ Smoking } & Never & 10.3 & 445 & 2.74 & $(2.50,3.01)$ \\
\hline & Past & 6.7 & & 1.58 & $(1.44,1.75)$ \\
\hline & Current & 4.0 & & & \\
\hline \multirow[t]{2}{*}{ Hypercholesterolemia } & Yes & 5.1 & 61 & 0.70 & $(0.64,0.77)$ \\
\hline & No & 7.2 & & & \\
\hline \multirow[t]{2}{*}{ Family history } & Yes & 4.8 & 108 & 0.63 & $(0.58,0.69)$ \\
\hline & No & 7.4 & & & \\
\hline \multirow[t]{2}{*}{ Previous MI } & Yes & 11.7 & 293 & 2.11 & $(1.93,2.29)$ \\
\hline & No & 5.9 & & & \\
\hline \multirow[t]{2}{*}{ Previous angina } & Yes & 8.3 & 81 & 1.43 & $(1.32,1.54)$ \\
\hline & No & 6.0 & & & \\
\hline \multirow[t]{2}{*}{ Cerebrovascular disease } & Yes & 15.5 & 99 & 2.56 & $(2.13,3.08)$ \\
\hline & No & 6.7 & & & \\
\hline \multirow[t]{2}{*}{ Prior bypass surgery } & Yes & 10.7 & 41 & 1.66 & $(1.42,1.93)$ \\
\hline & No & 6.7 & & & \\
\hline \multirow[t]{2}{*}{ Prior angioplasty } & Yes & 5.6 & 4.4 & 0.80 & $(0.64,0.98)$ \\
\hline & No & 7.0 & & & \\
\hline \multirow[t]{3}{*}{ Infarct location } & Anterior & 9.9 & 361 & 2.11 & $(1.96,2.28)$ \\
\hline & Inferior & 5.0 & & & \\
\hline & Other & 7.2 & & 1.48 & $(1.20,1.82)$ \\
\hline \multirow[t]{4}{*}{ Killip class } & 1 & 5.1 & 2343 & & \\
\hline & ॥ & 13.6 & & 2.95 & $(2.70,3.23)$ \\
\hline & III & 32.2 & & 8.91 & $(7.63,10.40)$ \\
\hline & IV & 57.8 & & 25.68 & $(21.96,30.03)$ \\
\hline
\end{tabular}

$\mathrm{MI}$ indicates myocardial infarction; $\mathrm{OR}$, odds ratio; and $\mathrm{Cl}$, confidence interval.

and conversely, risk differences among Killip classes were less in older patients.

Fig 2 shows adjusted ORs for mortality for each of the variables in the final multivariable model. The ORs were most dramatic for factors such as age and Killip class, each exhibiting a highly significant relation with mortality in the multivariable regression analysis. After adjustment for all other factors, the OR associated with Killip class III versus I for an average-age patient was 4.37 (95\% CI, 3.34 to 5.71), whereas the OR for Killip class IV versus I was 7.86 (95\% CI, 5.88 to 10.49 ).

The model formulation that includes all factors in Table 3 is given in the "Appendix." With the coefficients in this model and the ORs in Fig 2, relative effects of various clinical factors can be quantified. For example, each additional year of age in Killip class I patients imparts a risk equal to a $2 \mathrm{~mm} \mathrm{Hg}$ reduction in systolic blood pressure (for patients presenting with systolic blood pressures below $120 \mathrm{~mm} \mathrm{Hg}$ ) or to treating patients 45 minutes later. An additional 7 years of age confers a risk similar to the difference between an inferior and anterior MI, and the risk reduction associated with use of accelerated TPA is equivalent to a reduction in age of about 3 years.

The index of predictive discrimination for this model, namely the area under the receiver operating characteristic curve, was 0.836 , reflecting excellent ability of the model to discriminate between patients who do and do not have a fatal event within 30 days.

Fig 3 shows the calibration (reliability) of the model predictions. Patients were divided into deciles of risk according to their model predictions, and the observed mortality rate among the patients in each decile was calculated and plotted against the average predicted probability. The points all fell very close to the $45^{\circ}$ line (perfect calibration), demonstrating excellent calibration of the predictions from this model. Table 4 illustrates the same concept for several arbitrarily chosen subgroups defined by specific clinical characteristics, namely sex, age, infarct location, and Killip class. The average predicted mortality for patients in each of these subgroups (even subgroups defined by a factor not included in the multivariable model, such as male and female patients) coincided very closely with the observed mortality, again reflecting excellent calibration of the model predictions. Results of the internal validation revealed very little overoptimism in the predictive discrimination of the model. The correction to the receiver operating characteristic area determined by cross validation was only 0.002 (reducing the value from 0.836 to 0.834 ). The bootstrapping technique produced exactly the same correction. As a result, the calibration curve in Fig 3 did not need an optimism correction. 

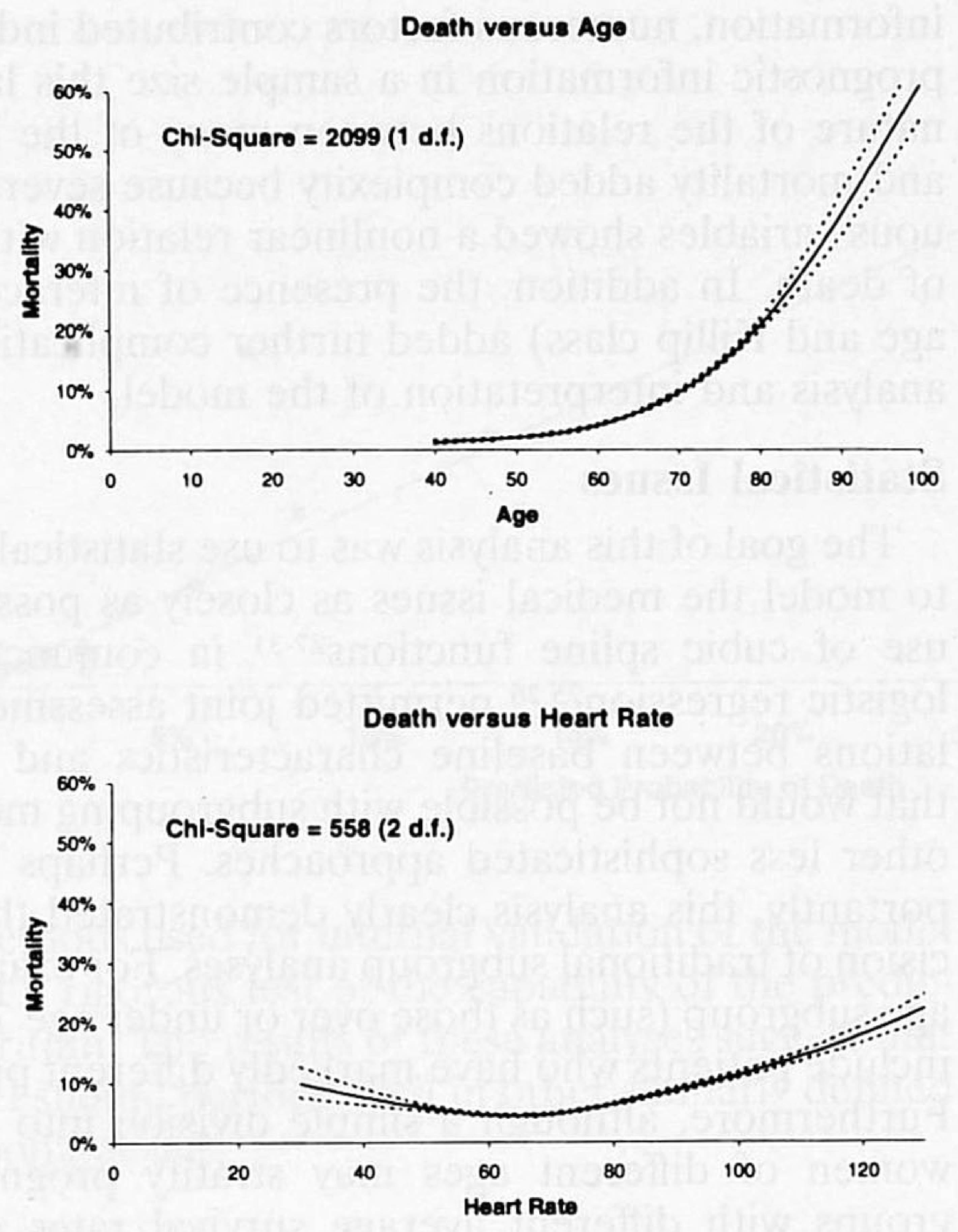

Death versus Height

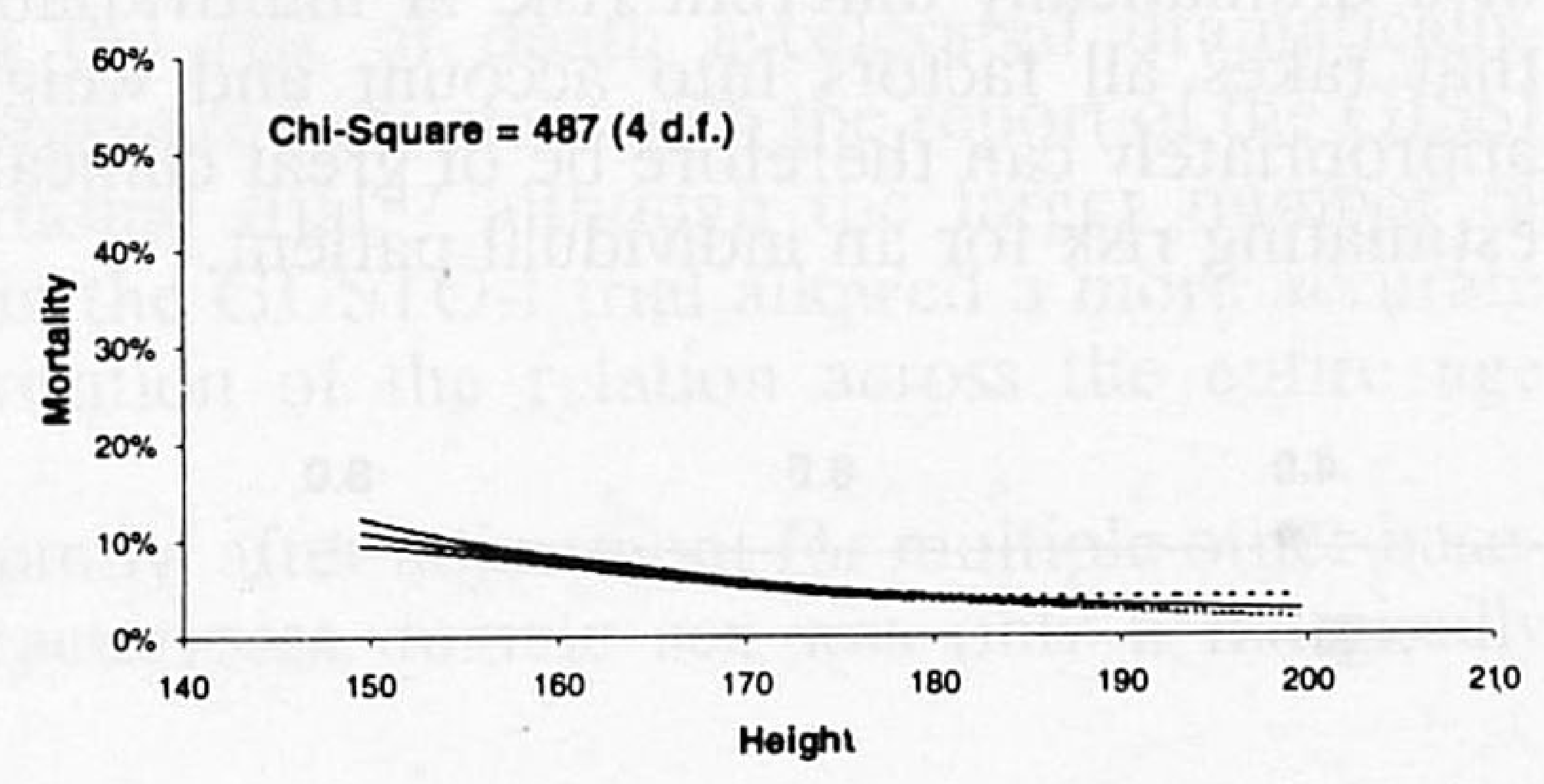

Death vs. Time to Treatment

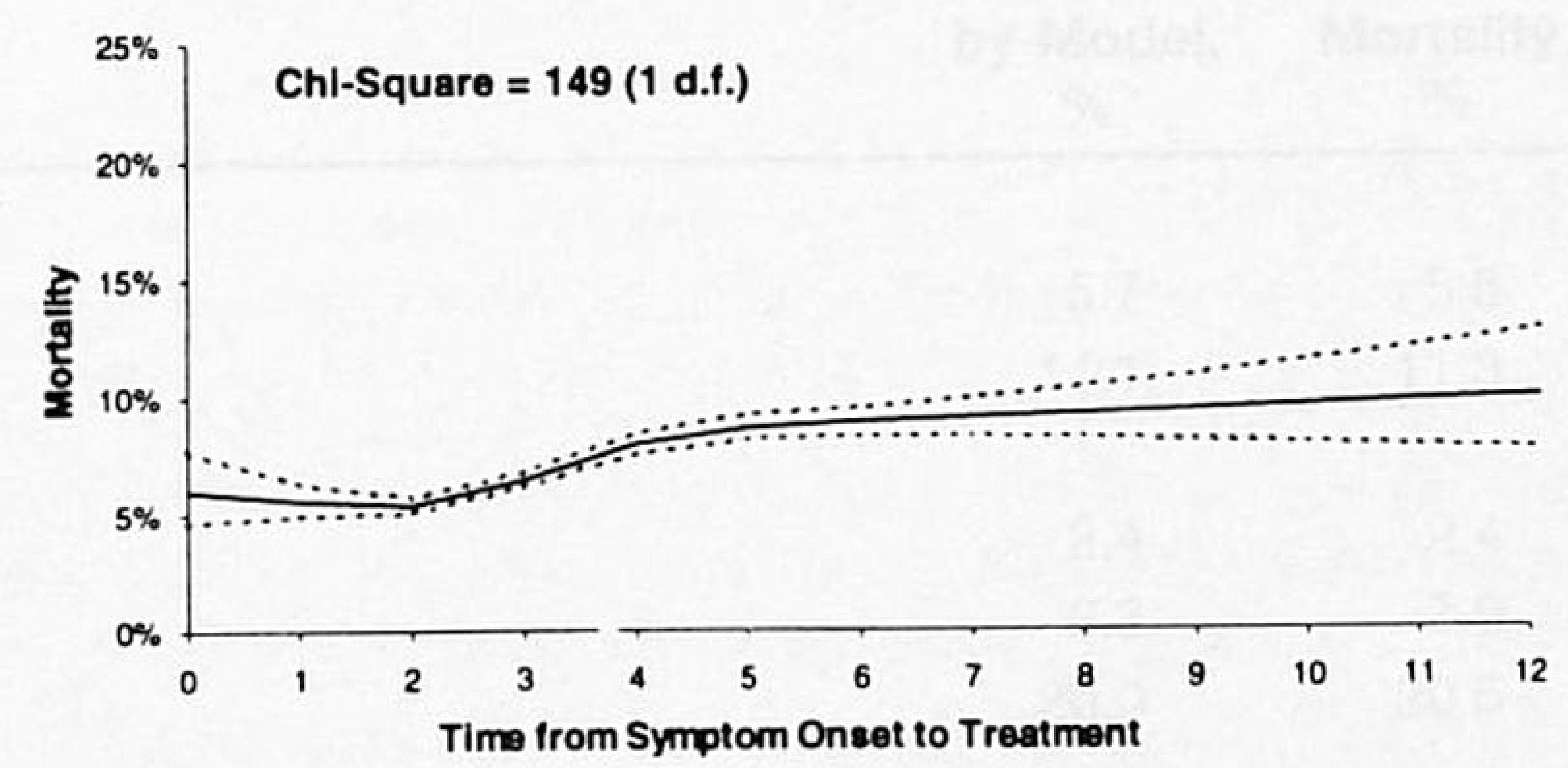

A perspective on the overall contribution of various components of the baseline clinical data to the prediction of mortality can be obtained by use of the global $\chi^{2}$ statistic from the logistic model as an index of prognostic information and a comparison of this index from the full model containing all the variables listed in Table 3 with reduced models containing a smaller number of variables. The likelihood ratio $\chi^{2}$ statistic for a model containing all of the prognostic factors in Table 3 was 4379. In contrast, this statistic for a model containing age alone was 2099 , meaning that age provides nearly half the prognostic information. Adding other variables provides an increased proportion of information; combining
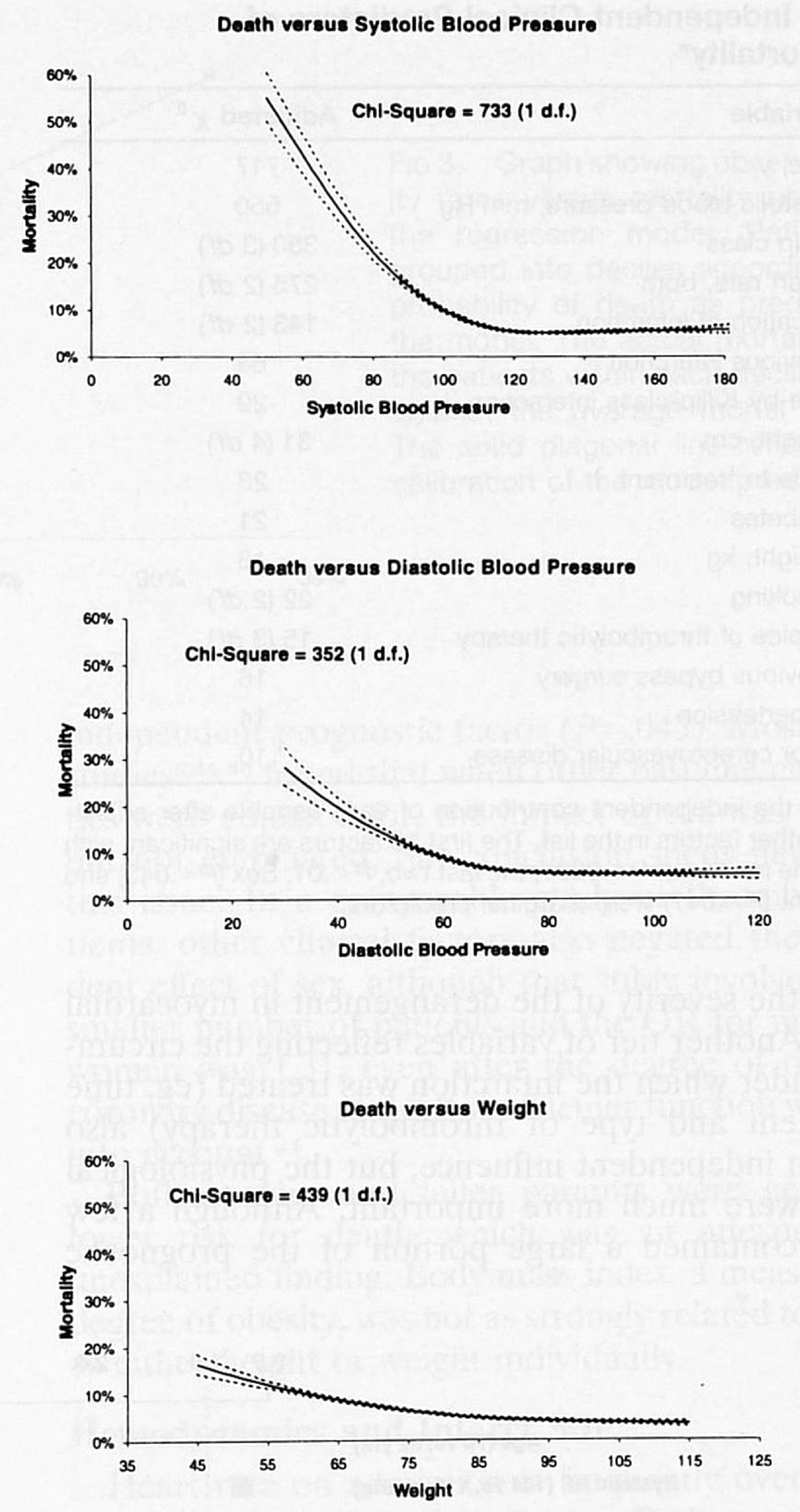

FIG 1. Plots showing unadjusted (univariate) relations between continuous baseline variables and 30-day mortality based on logistic regression. Each panel depicts the probability of death (solid curve) with $95 \% \mathrm{Cls}$ (dotted curves) as a function of the baseline variable. The degrees of freedom ( $d f$ ) associated with the $\chi^{2}$ statistic in each case depend on the complexity of the relation between the variable and the log odds of mortality. Where $d f=3$, the relation was nonlinear and characterized with cubic spline functions. Where $d f=1$, the relation was linear even though the plot shown here, which reflects mortality (rather than the log odds), exhibits a nonlinear relation. For heart rate (2df), two linear splines were used to model the relation. Age was measured in years, blood pressure in millimeters of mercury, heart rate in beats per minute, height in centimeters, weight in kilograms, and time to treatment in hours.

age, systolic blood pressure, Killip class, heart rate, infarct location, and age-by-Killip-class interaction provides approximately $90 \%$ of the total prognostic information contained in this array of baseline clinical characteristics.

\section{Discussion}

The clinical determinants of mortality in patients treated with thrombolytic therapy for ST-segment elevation within 6 hours of symptom onset are complex and multidimensional. Much of the important prognostic information was contained in the patient's age, location of the infarction, and physiological characteristics rep- 
TABLE 3. Independent Clinical Predictors of 30-Day Mortality *

\begin{tabular}{lc}
\hline Variable & Adjusted $\chi^{2}$ \\
\hline Age, y & 717 \\
Systolic blood pressure, $\mathrm{mm} \mathrm{Hg}$ & 550 \\
Killip class & $350(3 d f)$ \\
Heart rate, bpm & $275(2 d f)$ \\
Location of infarction & $143(2 d f)$ \\
Previous infarction & 64 \\
Age-by-Killip-class interaction & 29 \\
Height, cm & $31(4 d f)$ \\
Time to treatment, h & 23 \\
Diabetes & 21 \\
Weight, kg & 16 \\
Smoking & $22(2 d f)$ \\
Choice of thrombolytic therapy & $15(3 d f)$ \\
Previous bypass surgery & 16 \\
Hypertension & 14 \\
Prior cerebrovascular disease & 10 \\
\hline
\end{tabular}

*Indicates the independent contribution of each variable after adjustment for all other factors in the list. The first 10 factors are significant with $P<.00001$; the next four, $P<.0001$; the last two, $P<.01$. Sex $(P=.043)$ and US enrollment $(P=.047)$ were marginal predictors.

resenting the severity of the derangement in myocardial function. Another tier of variables reflecting the circumstances under which the infarction was treated (eg, time to treatment and type of thrombolytic therapy) also exerted an independent influence, but the physiological variables were much more important. Although a few variables contained a large portion of the prognostic information, numerous factors contributed independent prognostic information in a sample size this large. The nature of the relations between many of the attributes and mortality added complexity because several continuous variables showed a nonlinear relation with the risk of death. In addition, the presence of interactions (eg, age and Killip class) added further complication to the analysis and interpretation of the model.

\section{Statistical Issues}

The goal of this analysis was to use statistical methods to model the medical issues as closely as possible. The use of cubic spline functions ${ }^{27-31}$ in conjunction with logistic regression ${ }^{25,26}$ permitted joint assessment of relations between baseline characteristics and outcome that would not be possible with subgrouping methods or other less sophisticated approaches. Perhaps most importantly, this analysis clearly demonstrated the imprecision of traditional subgroup analyses. For example, any age subgroup (such as those over or under age 75) would include patients who have markedly different prognoses. Furthermore, although a simple division into men and women of different ages may stratify prognosis into groups with different average survival rates (eg, men $<70$ years versus women $>70$ years), the presence or absence of multiple other characteristics could place an individual patient within this broadly defined subgroup at a dramatically different risk. A multivariable model that takes all factors into account and weights them appropriately can therefore be of great clinical value in estimating risk for an individual patient.

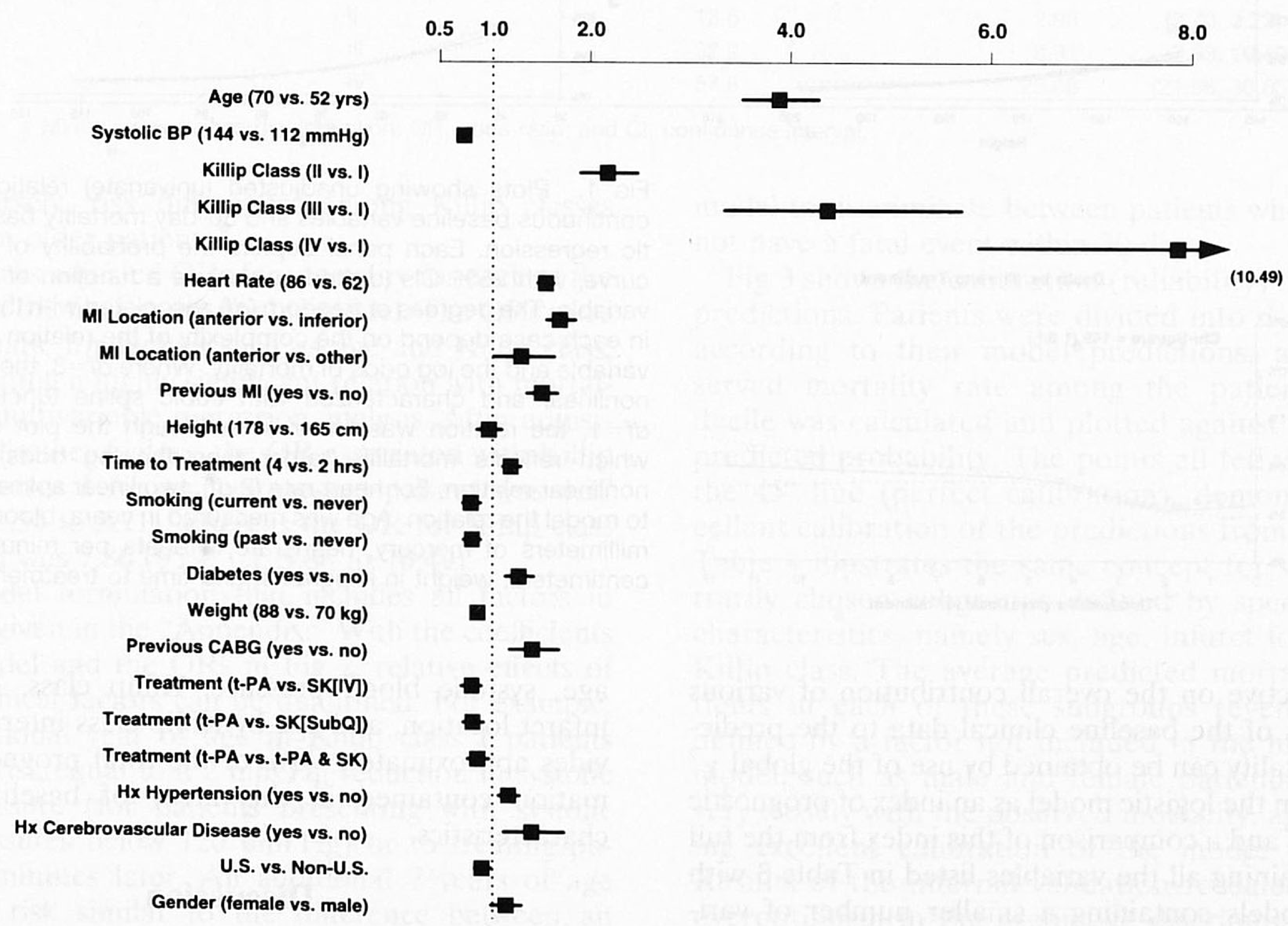

FIG 2. Graph showing ORs and $95 \%$ Cls for variables in the final multivariable mortality risk model (Table 3). Calculated from the model containing all the factors listed in Table 3 , each OR is adjusted to account for the other variables in the model. Also shown are adjusted ORs for the two marginally significant variables, sex and enrollment in the United States. For continuous variables, the value depicted reflects the odds of death for patients at the 75 th percentile of the distribution of the variable versus patients at the 25 th percentile. An $\mathrm{OR}$ of 1.0 represents no prognostic stratification; a value $>1$ reflects increased risk of death; a value $<1$ reflects reduced risk of death. $\mathrm{BP}$ indicates blood pressure; MI, myocardial infarction; CABG, coronary artery bypass surgery; TPA (t-PA), accelerated tissueplasminogen activator; SK, streptokinase; SubQ, subcutaneous; and $\mathrm{Hx}$, history. 


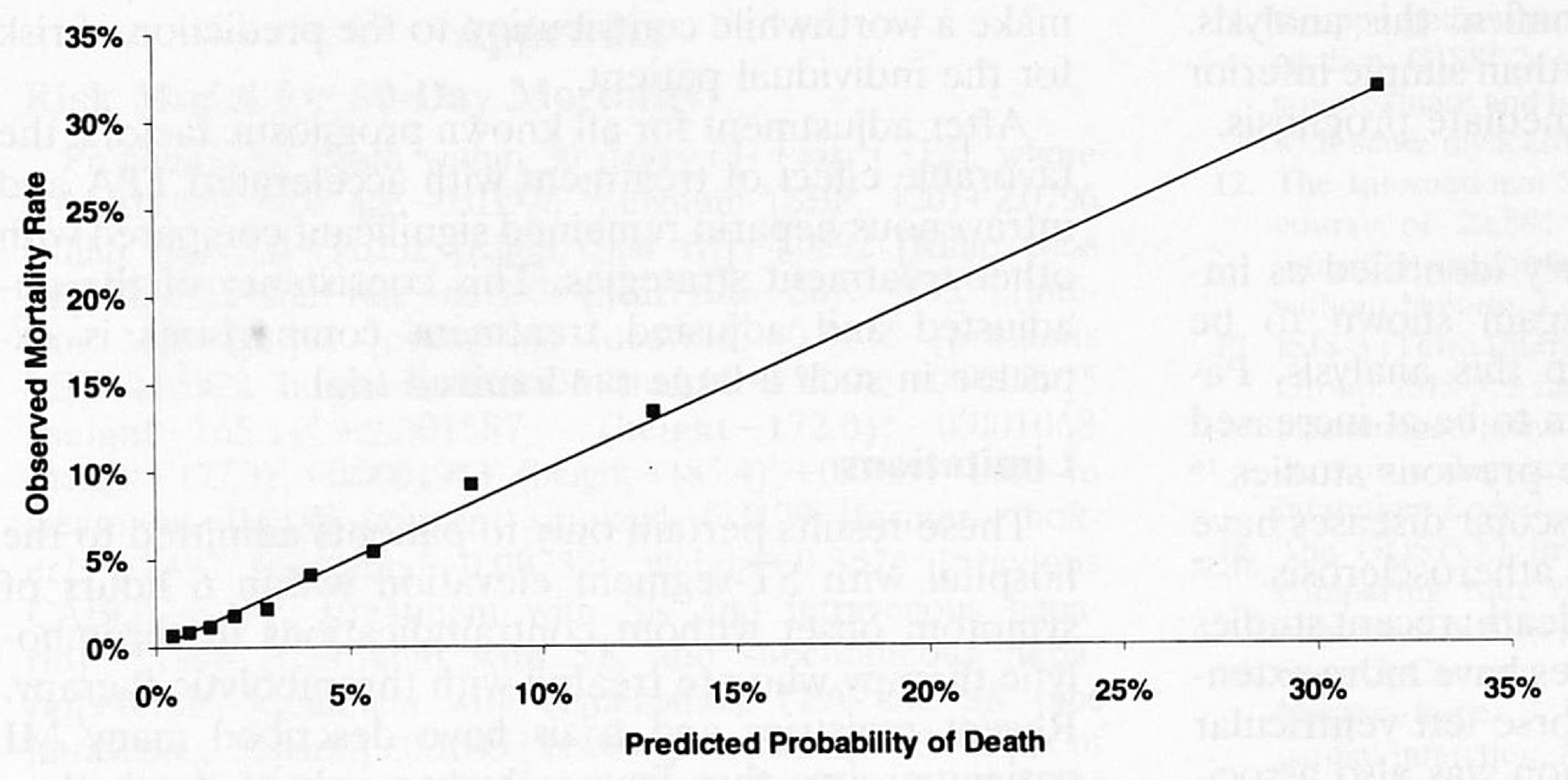

FIG 3. Graph showing observed mortality rates versus mortality predicted by the regression model. Patients were grouped into deciles according to their probability of death as predicted from the model. The actual mortality rate for the patients within each decile is plotted against the average model prediction. The solid diagonal line reflects perfect calibration of the model predictions.

The methods used for internal validation of the model represent a rigorous test of the capability of the prediction algorithm. The results of these analyses suggest that the model should perform well in other similarly defined patient populations.

\section{Demographics}

Age has been increasingly recognized as a critical determinant of outcome in patients with acute ischemic heart disease. The relation was relatively flat until age 60 , when the risk of death accelerated dramatically. These results are consistent with the report of the GISSI 2/International trial, ${ }^{12}$ although the larger number of patients in the GUSTO-I trial allowed a more accurate characterization of the relation across the entire age range.

Importantly, after adjustment for multiple other baseline characteristics, female sex was only a marginally

TABLE 4. Comparison of Predicted and Actual 30-Day Mortality in Selected Patient Subgroups

\begin{tabular}{|c|c|c|}
\hline Subgroup & $\begin{array}{c}\text { Mortality } \\
\text { Predicted } \\
\text { by Model, } \\
\%\end{array}$ & $\begin{array}{c}\text { Actual } \\
\text { Mortality, } \\
\% \\
\end{array}$ \\
\hline \multicolumn{3}{|l|}{ Sex } \\
\hline Male & 5.7 & 5.5 \\
\hline Female & 11.1 & 11.3 \\
\hline \multicolumn{3}{|l|}{ Age, y } \\
\hline$<60$ & 2.4 & 2.4 \\
\hline $60-75$ & 8.3 & 7.9 \\
\hline$>75$ & 20.0 & 20.5 \\
\hline \multicolumn{3}{|l|}{ Infarct location } \\
\hline Anterior & 10.0 & 9.9 \\
\hline Inferior & 5.0 & 5.0 \\
\hline \multicolumn{3}{|l|}{ Killip class } \\
\hline 1 & 5.1 & 5.1 \\
\hline II & 13.9 & 13.6 \\
\hline III & 32.7 & 32.2 \\
\hline IV & 57.8 & 57.8 \\
\hline \multicolumn{3}{|l|}{ Factor combinations } \\
\hline Female, age $>75$ & 22.6 & 22.9 \\
\hline Female, age $>75$, inferior $\mathrm{MI}$ & 17.3 & 16.6 \\
\hline Female, age $>75$, inferior MI, Killip class I & 14.7 & 14.1 \\
\hline Male, age $<60$ & 2.2 & 2.2 \\
\hline Male, age $<60$, anterior $\mathrm{MI}$ & 3.1 & 3.5 \\
\hline Male, age $<60$, anterior MI, Killip class I & 2.0 & 2.3 \\
\hline
\end{tabular}

$\mathrm{Ml}$ indicates myocardial infarction. independent prognostic factor $(P=.043)$. Most previous studies ${ }^{8,4-46}$ found that when other baseline characteristics were adjusted for, the impact of sex was weakened but not eliminated; our conclusion sheds new light on this issue. In a comparable study of thrombolytic patients, other clinical factors also negated the independent effect of sex, although that study involved a much smaller number of patients and the OR for mortality in women was 1.31 , even after the degree of obstructive coronary disease and left ventricular function were taken into account. ${ }^{44}$

Both heavier and taller patients were generally at lower risk for death, which was an unexpected and unexplained finding. Body mass index, a measure of the degree of obesity, was not as strongly related to outcome as either height or weight individually.

\section{Hemodynamics and Infarct Site}

Heart rate on admission is frequently overlooked as an important prognostic indicator. Patients with significant sinus tachycardia or bradycardia on hospital admission had an increased risk of death. Previous studies have identified sinus tachycardia as an independent prognostic factor ${ }^{47}$ presumably because it represents activation of the sympathetic nervous system as a consequence of infarction size. The physiological significance of bradycardia may represent a variety of underlying pathophysiological problems, ranging from conduction system disturbances to agonal rhythms.

Systolic blood pressure is a critical factor. It is no surprise that hypotension was associated with a decrease in survival, but the level at which prognosis began to decline $(120 \mathrm{~mm} \mathrm{Hg})$ is somewhat higher than expected. We could not find an effect of elevated blood pressure on survival. Many patients with extreme elevations of systolic blood pressure were excluded from GUSTO-I because of concern about the risk of intracranial hemorrhage, but 602 patients with a systolic blood pressure exceeding $180 \mathrm{~mm} \mathrm{Hg}$ were included.

The relation between outcome and location of infarction is complicated. Multiple previous studies have reported that patients with anterior infarction have the highest risk of death, ${ }^{47-49}$ and isolated inferior infarction has been associated with the lowest risk. A detailed analysis from the GISSI I trial showed that the number of leads with ST-segment elevation was more important than infarction location, ${ }^{50}$ but ECG information from 
GUSTO-I is not yet available to confirm this analysis. We found that infarct location other than simple inferior or anterior infarctions had an intermediate prognosis.

\section{Medical History}

Several baseline features previously identified as important prognostic factors were again shown to be important predictors of mortality in this analysis. Patients with prior MI have been shown to be at increased risk of subsequent death in multiple previous studies. ${ }^{16}$ Similarly, peripheral and cerebral vascular diseases have been associated with more extensive atherosclerosis. ${ }^{51,52}$ Diabetes was a major risk factor for death; recent studies have shown that patients with diabetes have more extensive coronary atherosclerosis and worse left ventricular function..$^{53,54} \mathrm{~A}$ history of hypertension was also associated with increased risk, although the strength of the relation was much less than that of diabetes. At least a portion of the increased risk may be due to heightened risk of stroke.

The influences of smoking, family history, and elevated cholesterol were paradoxical: they were associated with lower mortality despite being traditional risk factors for coronary artery disease. Several other studies also reported lower mortality in patients with a history of smoking. $21,55,56$ We presume that these relations are mediated by the association of these risk factors with premature atherosclerosis and thrombotic occlusion: the acute event occurs in a younger patient with less overall atherosclerosis and other comorbidity or is precipitated by a lesser stimulus, which may respond better to thrombolytic therapy. Despite this construct, we were unable to demonstrate that adjustment for other noninvasive measures of severity of illness completely explained the more benign prognosis of patients who were current or past smokers. Detailed assessment of coronary angiographic findings will be required to understand these relations more clearly.

The influences of prior percutaneous coronary angioplasty and coronary bypass grafting are complicated. Because most patients undergoing initial angioplasty have single-vessel disease, it is not surprising that they have a better prognosis than those who have an array of single-, double-, and triple-vessel disease. No previous studies included enough patients with prior angioplasty to allow comparison. The negative prognostic implications of prior coronary artery bypass grafting probably reflect the presence of more left ventricular dysfunction and multivessel coronary disease, leaving patients at increased risk of adverse outcomes in the setting of an acute event.

\section{Modifiable Factors}

Of the predictors of adverse outcome that can be modified, time from symptom onset to hospital arrival or treatment is the most important. After adjustment for other factors in the model, each additional hour was associated with a measurable increase in the risk of death. This relation, however, was not linear for reasons that are unclear.

After adjustment for other baseline characteristics, treatment in the United States (compared with other countries) was marginally associated with a better prognosis. The small difference $(P=.047)$ was not enough to make a worthwhile contribution to the prediction of risk for the individual patient.

After adjustment for all known prognostic factors, the favorable effect of treatment with accelerated TPA and intravenous heparin remained significant compared with other treatment strategies. This consistency of the unadjusted and adjusted treatment comparisons is expected in such a large randomized trial.

\section{Limitations}

These results pertain only to patients admitted to the hospital with ST-segment elevation within 6 hours of symptom onset without contraindications to thrombolytic therapy who are treated with thrombolytic therapy. Recent registries and trials have described many MI patient groups that have a higher risk of death than those in this analysis. Patients with contraindications to thrombolytic therapy have the highest mortality, ${ }^{57}$ and those with an acute MI without ST-segment elevation have an intermediate risk. ${ }^{58}$ Though many of the same factors identified in this analysis would be expected to relate to mortality, the quantitative relations described here may not apply.

Additional clinical measurements not included in these analyses would also be expected to add to the prognostic model, especially additional ECG and angiographic information. Recent studies show that detailed measures of ST-segment elevation and T-wave height may provide substantial information about prognosis, ${ }^{50,59}$ independent of infarction location or other physiological factors. Also, coronary anatomy, ${ }^{60}$ left ventricular function, ${ }^{61}$ and patency and degree of mitral regurgitation ${ }^{62}$ would be expected to play major roles in determination of prognosis. Because most patients with acute ischemic disease do not undergo acute cardiac catheterization, using this information for risk assessment would not be meaningful in most patients. However, the information available from the GUSTO-I angiographic substudy ${ }^{63}$ provides insight into the pathophysiological basis for the risks associated with various baseline characteristics.

\section{Conclusions}

Careful modeling of 30-day mortality, using the large population of GUSTO-I patients and data routinely collected at initial presentation, has yielded a method to accurately predict short-term risk in individual patients. This risk-assessment algorithm should be useful clinically in managing patients who are candidates for thrombolytic therapy. Many prognostic factors identified in this analysis cannot be modified, but the importance of early detection and treatment of MI remained evident: even after adjustment for physiological measures of hemodynamic deterioration, time to treatment and type of thrombolytic therapy remained independent prognostic factors. Only by considering the effect of multiple characteristics, including age, medical history, physiological significance of the current event, and medical treatment, can the prognosis of an individual patient be estimated with confidence.

\section{Acknowledgments}

This study was funded by grants from Bayer, CIBA-Corning, Genentech, ICI Pharmaceuticals, and Sanofi Pharmaceuticals. 


\section{Appendix}

\section{Risk Model for 30-Day Mortality}

Probability of death within 30 days $=1 /[1+\exp (-\mathrm{L})]$, where $\mathrm{L}=3.812+0.07624$ age -0.03976 minimum (SBP, 120)+2.0796 [Killip class II] +3.6232 [Killip class III] +4.0392 [Killip class IV] -0.02113 heart rate +0.03936 (heart rate -50$)_{+}-0.5355$ [inferior $\mathrm{MI}$ ] -0.2598 [other MI location] +0.4115 [previous MI] -0.03972 height +0.0001835 (height -154.9$)_{+}^{3}-0.0008975$ (height -165.1$)_{+}^{3}+0.001587 \quad$ (height -172.0$)_{+}^{3}-0.001068$ (height -177.3$)_{+}^{3}+0.0001943$ (height -185.4$)_{+}^{3}+0.09299$ time to treatment-0.2190 [current smoker]-0.2129 [former smoker] +0.2497 [diabetes] -0.007379 weight +0.3524 [previous $\mathrm{CABG}]+0.2142$ [treatment with SK and intravenous heparin] +0.1968 [treatment with SK and subcutaneous heparin] +0.1399 [treatment with combination TPA and SK plus intravenous heparin] +0.1645 [hx of hypertension] $+0.3412[\mathrm{hx}$ of cerebrovascular disease] -0.02124 age $\cdot[$ Killip class II] -0.03494 age $\cdot[$ Killip class III] -0.03216 age $\cdot$ [Killip class IV].

Explanatory notes.

1. Brackets are interpreted as $[\mathrm{c}]=1$ if the patient falls into category $\mathrm{c},[\mathrm{c}]=0$ otherwise.

$2 .(x)_{+}=x$ if $x>0,(x)_{+}=0$ otherwise.

3. For systolic blood pressure (SBP), values $>120 \mathrm{~mm} \mathrm{Hg}$ are truncated at 120 .

4. For time to treatment, values $<2$ hours are truncated at 2 .

5. The measurement units for age are years; for blood pressure, millimeters of mercury; for heart rate, beats per minute; for height, centimeters; for time to treatment, hours; and for weight, kilograms.

6. "Other" MI location refers to posterior, lateral, or apical but not anterior or inferior.

7. CABG indicates coronary artery bypass grafting; SK, streptokinase; and hx, history.

\section{References}

1. Kennedy JW, Martin GV, Davis KB, Maynard C, Stadius M, Sheehan FH, Ritchie JL. The Western Washington Intravenous Streptokinase in Acute Myocardial Infarction Randomized Trial. Circulation. 1988;77:345-352.

2. Gruppo Italiano per lo Studio della Streptochinasi Nell-Infarto Miocardico (GISSI). Effectiveness of intravenous thrombolytic treatment in acute myocardial infarction. Lancet. 1986;1:397-401.

3. ISIS-2 Collaborative Group. Randomised trial of intravenous streptokinase, oral aspirin, both, or neither among 17,187 cases of suspected acute myocardial infarction: ISIS-2. Lancet. 1988;2:349-360.

4. Wilcox RG, von der Lippe G, Olsson CB, Jensen G, Skene AM, Hampton JR. Trial of tissue plasminogen activator for mortality reduction in acute myocardial infarction: Anglo-Scandinavian Study of Early Thrombolysis (ASSET). Lancet. 1988;2:525-530.

5. The AIMS Trial Study Group. Effect of intravenous APSAC on mortality after acute myocardial infarction. Lancet. 1988;1:545-549.

6. Topol EJ, Califf RM, George BS, Kereiakes DJ, Abbottsmith CW, Candela RJ, Lee KL, Pitt B, Stack RS, O'Neill WW, for the Thrombolysis and Angioplasty in Myocardial Infarction (TAMI) Study Group. A randomized trial of immediate versus delayed elective angioplasty after intravenous tissue plasminogen activator in acute myocardial infarction. $N$ Engl J Med. 1987;317:581-588.

7. The TIMI Research Group. Immediate versus delayed catheterization and angioplasty following thrombolytic therapy for acute myocardial infarction. JAMA. 1988;260:2849-2858.

8. Weaver WD, Cerqueira M, Hallstrom AP, Litwin PE, Martin JS, Kudenchuk PJ, Eisenberg M. Prehospital-initiated versus hospitalinitiated thrombolytic therapy: the Myocardial Infarction Triage and Intervention Trial. JAMA. 1993;270:1211-1216.

9. Grines CL, Browne KF, Marco J, Rothbaum D, Stone GW, O'Keefe J, Overlie P, Donohue B, Chelliah N, Timmis GC, Vlietstra RE, Strzelecki M, Puchrowicz-Ochocki S, O'Neill WW, for the Primary Angioplasty in Myocardial Infarction Study Group. A comparison of immediate angioplasty with thrombolytic therapy for acute myocardial infarction. N Engl J Med. 1993;328:673-679.

10. White HD, Norris RM, Brown MA, Takayama M, Maslowski A, Bass NM, Ormiston JA, Whitlock T. Effect of intravenous streptokinase on left ventricular function and early survival after acute myocardial infarction. N Engl J Med. 1987;317:850-855.
11. Gruppo Italiano per lo Studio della Sopravvivenza nell'Infarto Miocardico. GISSI-2: a factorial randomised trial of alteplase versus streptokinase and heparin versus no heparin among 12490 patients with acute myocardial infarction. Lancet. 1990;336:65-71.

12. The International Study Group. In-hospital mortality and clinical course of 20,891 patients with suspected acute myocardial infarction randomised between alteplase and streptokinase with or without heparin. Lancet. 1990;336:71-79.

13. ISIS-3 (Third International Study of Infarct Survival) Collaborative Group. ISIS-3: a randomised comparison of streptokinase vs. tissue plasminogen activator vs. anistreplase and of aspirin plus heparin vs. aspirin alone among 41,299 cases of suspected acute myocardial infarction. Lancet. 1993;339:753-770.

14. The GUSTO-I Investigators. An international randomized trial comparing four thrombolytic strategies for acute myocardial infarction. N Engl J Med. 1993;329:673-682.

15. Sanz G, Castaner A, Betriu A, Magrina J, Roig E, Coll S, Pare JC, Navarra-Lopez F. Determinants of prognosis in survivors of myocardial infarction. N Engl J Med. 1982;306:1065-1070.

16. Norris RM, Brandt PWT, Caughey DE, Lee AJ, Scott PJ. A new coronary prognostic index. Lancet. 1969;1:274-278.

17. Moss AJ, DeCamilla J, Davis H, Bayer L. The early posthospital phase of myocardial infarction: prognostic stratification. Circulation. 1976;54:58-64

18. The Multicenter Postinfarction Research Group. Risk stratification and survival after myocardial infarction from the Multicenter PostInfarction Research Group. N Engl J Med. 1983;309:331-336.

19. Dubois C, Pierard LA, Albert A, Smeets J-P, Demoulin J-C, Boland J, Kulbertus HE. Short-term risk stratification at admission based on simple clinical data in acute myocardial infarction. $\mathrm{Am} \mathrm{J}$ Cardiol. 1988;61:216-219.

20. Hillis DK, Forman S, Braunwald E, for the Thrombolysis in Myocardial Infarction (TIMI) Phase II Coinvestigators. Risk stratification before thrombolytic therapy in patients with acute myocardial infarction. J Am Coll Cardiol. 1990;16:313-315.

21. Mueller HS, Cohen LS, Braunwald E, Forman S, Feit F, Ross A, Schweiger M, Cabin H, Davison R, Miller D, Solomon R, Knatterud GL, for the TIMI Investigators. Predictors of early morbidity and mortality after thrombolytic therapy of acute myocardial infarction: analyses of patient subgroups in the Thrombolysis in Myocardial Infarction (TIMI) Trial, Phase II. Circulation. 1992;85:1254-1264.

22. Maynard C, Weaver D, Litwin PE, Martin JS, Kudenchuk PJ, Dewhurst TA, Eisenberg MS, Hallstrom AP, Chambers J, for the MITI Project Investigators. Hospital mortality in acute myocardial infarction in the era of reperfusion therapy (the Myocardial Infarction Triage and Intervention Project). $\mathrm{Am} \mathrm{J}$ Cardiol. 1993;72:877-882.

23. Volpi A, DeVita C, Franzosi MG, Geraci E, Maggioni AP, Mauri F, Negri E, Santoro E, Tavazzi L, Tognoni G, for the Ad hoc Working Group of the Gruppo Italiano per lo Studio della Sopravvivenza nell-Infarto Miocardico (GISSI-2) Data Base. Determinants of 6-month mortality in survivors of myocardial infarction after thrombolysis: results of the GISSI-2 data base. Circulation. 1993;88:416-429.

24. Califf RM, Topol EJ, Stack RS, Ellis SG, George BS, Kereiakes DJ, Samaha JK, Worley SJ, Anderson JL, Harrelson-Woodlief L, Wall TC, Phillips HR III, Abbottsmith CW, Candela RJ, Flanagan WH, Sasahara AA, Mantell SJ, Lee KL, for the TAMI Study Group. Evaluation of combination thrombolytic therapy and timing of cardiac catheterization in acute myocardial infarction: results of Thrombolysis and Angioplasty in Myocardial Infarction, phase 5 randomized trial. Circulation. 1991;83:1543-1556.

25. Walker SH, Duncan DB. Estimation of the probability of an event as a function of several independent variables. Biometrika. 1967;54:167-179.

26. Hosmer DW, Lemeshow S. Applied Logistic Regression. New York, NY: John Wiley \& Sons, Inc; 1989.

27. Harrell FE Jr, Pollock BG, Lee KL. Graphical methods for the analysis of survival data. Proc 12th Annual SAS Users Group International Conference. Cary, NC: SAS Institute Inc; 1987:1107-1115.

28. Smith PL. Splines as a useful and convenient statistical tool. Am Statistician. 1979;33:57-62.

29. Stone CJ, Koo C. Additive splines in statistics. Proc Statistical Computing Section. Alexandria, Va: American Statistical Association: $1985: 45-48$.

30. Devlin TF, Weeks BJ. Spline functions for logistic regression modeling. Proc 11th Annual SAS Users Group International Conference. Cary, NC: SAS Institute Inc: 1986:646-651. 
31. Harrell FE Jr, Lee KL, Pollock BG. Regression models in clinical studies: determining relationships between predictors and response. J Natl Cancer Inst. 1988;80:1198-1202.

32. Chambers JM, Hastie TJ. Statistical Models in S. Pacific Grove, Calif: Wadsworth \& Brooks/Cole; 1992.

33. Harrell FE Jr. Transcan: S function for transformation and imputation using canonical variates. Available from statlibalib.stat.cmu edu; 1993. Request 'send transcan from S.'

34. Kuhfeld WF. The PRINQUAL procedure. In: SAS/STAT User's Guide. Cary, NC: SAS Institute, Inc; 1990;2:1265-1323.

35. Efron B. Estimating the error rate of a prediction role: improvement on cross-validation. J Am Statist Assn. 1983;78:316-331.

36. Gong G. Cross-validation, the jackknife, and the bootstrap: excess error estimation in forward logistic regression. J Am Statist Assn. 1986;81:108-113.

37. Efron B. How biased is the apparent error rate of a prediction rule? J Am Statist Assn. 1986;81:461-470.

38. Efron B, Gong G. A leisurely look at the bootstrap, the jackknife, and cross-validation. Am Statistician. 1983;37:36-48.

39. Efron B, Tibshirani R. An Introduction to the Bootstrap. New York, NY: Chapman and Hall; 1993.

40. Harrell FE Jr. Design: S functions for biostatistical/epidemiologic modeling, testing, estimation, validation, graphics, and prediction. Available from statlibalib.stat.cmu.edu; 1994. Request 'send design from S.'

41. Hanley JA, McNeil BJ. The meaning and use of the area under a receiver operating characteristic (ROC) curve. Radiology. 1982;143:29-36.

42. Kendall DG. Rank Correlation Methods. 3rd ed. London: Charles Griffin; 1962

43. Yates JF. Judgment and Decision Making. Englewood Cliffs, NJ: Prentice Hall; 1990.

44. Lincoff AM, Califf RM, Ellis SG, Sigmon KN, Lee KL, Leimberger JD, Topol EJ, for the Thrombolysis and Angioplasty in Myocardial Infarction Study Group. Thrombolytic therapy for women with myocardial infarction: is there a gender gap? J Am Coll Cardiol. 1993;22:1780-1787.

45. Becker RC, Terrin M, Ross R, Knatterud GL, Desvigne-Nickens P, Gore JM, Braunwald E, for the Thrombolysis in Myocardial Infarction Investigators. Comparison of clinical outcomes for women and men after acute myocardial infarction. Ann Intern Med. 1994;120:638-645.

46. White HD, Barbash GI, Modan M, Simes J, Diaz R, Hampton JR, Heikkila J, Kristinsson A, Moulopoulos S, Paolasso EAC, Van der Werf T, Pehrsson K, Sandoe E, Wilcox RG, Verstraete M, von der Lippe G, Van de Werf F, for the Investigators of the International Tissue Plasminogen Activator/Streptokinase Mortality Study. After correcting for worse baseline characteristics, women treated with thrombolytic therapy for acute myocardial infarction have the same mortality and morbidity as men except for a higher incidence of hemorrhagic stroke. Circulation. 1993;88:2097-2103.

47. Crimm A, Severance HW Jr, Coffey K, McKinnis R, Wagner GS, Califf RM. Prognostic significance of isolated sinus tachycardia during first three days of acute myocardial infarction. Am J Med. 1984;73:983-988.

48. Taylor GJ, Humphries JO, Millits ED, Pitt B, Schulze RA, Griffith LS, Achuff SC. Predictors of clinical course, coronary anatomy and left ventricular function after recovery from acute myocardial infarction. Circulation. 1980;62:960-970.

49. Stone PH, Raabe DS, Jaffe AS, Gustafson N, Muller JE, Turi ZG, Rutherford JD, Poole WK, Passamani E, Willerson JT, Sobel BE, Robertson T, Braunwald E, for the MILIS Group. Prognostic significance of location and type of myocardial infarction: independent adverse outcome associated with anterior location. $\mathrm{J} \mathrm{Am}$ Coll Cardiol. 1988;11:453-463.

50. Mauri F, Gasparini M, Barbonaglia L, Santoro E, Franzosi KMG, Tognoni G, Rovelli F. Prognostic significance of the extent of myocardial injury in acute myocardial infarction treated by streptokinase (the GISSI Trial). Am J Cardiol. 1989;63:1291-1295.

51. The Dutch TIA Trial Study Group. Predictors of major vascular events in patients with a transient ischemic attack or nondisabling stroke. Stroke. 1993;24:527-531.

52. Kornowski R, Goldbourt U, Zion M, Mandelzweig L, Kaplinsky E, Levo Y, Behar S, for the SPRINT Study Group. Predictors and long-term prognostic significance of recurrent infarction in the year after a first myocardial infarction. Am J Cardiol. 1993;72:883-888.

53. Granger CB, Califf RM, Young S, Candela R, Samaha J, Worley S, Kereiakes DJ, Topol EJ, for the Thrombolysis and Angioplasty in Myocardial Infarction (TAMI) Study Group. Outcome of patients with diabetes mellitus and acute myocardial infarction treated with thrombolytic agents. J Am Coll Cardiol. 1993;21:920-925.

54. Barbash GI, White HD, Modan M, Van de Werf F. Significance of diabetes mellitus in patients with acute myocardial infarction receiving thrombolytic therapy. J Am Coll Cardiol. 1993;22:707-713.

55. Barbash GI, White HD, Modan M, Diaz R, Hampton JR, Heikkila J, Kristinsson A, Moulopoulos S, Paolasso EAC, Van der Werf T, Pehrsson K, Sandoe E, Simes J, Wilcox RG, Verstraete M, Von der Lippe G, Van de Werf F. Significance of smoking in patients receiving thrombolytic therapy for acute myocardial infarction: experience gleaned from the International Tissue Plasminogen Activator/Streptokinase Mortality Trial. Circulation. 1993;87:53-58.

56. Ockene IS, Ockene JK. Smoking after acute myocardial infarction: a good thing? Circulation. 1993;87:297-299.

57. Weaver WD, Litwin PE, Martin JS, Kudenchuk PJ, Maynard C, Eisenberg MS, Ho MT, Cobb LA, Kennedy JW, Wirkus MS, for the MITI Project Group. Effect of age on use of thrombolytic therapy and mortality in acute myocardial infarction. $\mathrm{J} \mathrm{Am}$ Coll Cardiol. 1991;18:657-672.

58. Cragg DR, Friedman HZ, Bonema JD, Jaiyesimi IA, Ramos RG, Timmis GC, O'Neill WW, Schreiber TL. Outcome of patients with acute myocardial infarction who are ineligible for thrombolytic therapy. Ann Intern Med. 1991;115:173-177.

59. Cairns CB, Niemann JT, Selker HP, Laks MM. Computerized version of the time-insensitive predictive instrument: use of the $\mathrm{Q}$ wave, ST-segment, T wave and patient history in the diagnosis of acute myocardial infarction by the computerized ECG. J Electrocardiol. 1992;24:46-49.

60. Muller DW, Topol EJ, Ellis SG, Sigmon KN, Lee K, Califf RM, for the Thrombolysis and Angioplasty in Myocardial Infarction (TAMI) Study Group. Multivessel coronary artery disease: a key predictor of short-term prognosis after reperfusion therapy for acute myocardial infarction. Am Heart J. 1991;121:1042-1049.

61. Grines CL, Topol EJ, Califf RM, Stack RS, George BS, Kereiakes D, Boswick JM, Kline E, O'Neill WW, for the TAMI Study Group. Prognostic implications and predictors of enhanced regional wall motion of the noninfarct zone after thrombolysis and angioplasty therapy of acute myocardial infarction. Circulation. 1989;80:245-253.

62. Tcheng JE, Jackman JD Jr, Nelson CL, Gardner LH, Smith LR, Rankin JS, Califf RM, Stack RS. Outcome of patients sustaining acute ischemic mitral regurgitation during myocardial infarction. Ann Intern Med. 1992;117:18-24.

63. The GUSTO-I Angiographic Investigators. The effects of tissue plasminogen activator, streptokinase, or both on coronary artery patency, ventricular function, and survival after acute myocardial infarction. N Engl J Med. 1993;329:1615-1622. 